\title{
Patient-Reported Outcomes From Patients With Heart Failure Participating in the Future Patient Telerehabilitation Program: Data From the Intervention Arm of a Randomized Controlled Trial
}

Cathrine Skov Schacksen ${ }^{1}$, MSc; Anne-Kirstine Dyrvig ${ }^{2}$, MSc, PhD; Nanna Celina Henneberg ${ }^{1}$, BSc; Josefine Dam Gade $^{1}$, MSc; Helle Spindler ${ }^{3}$, MSc, PhD; Jens Refsgaard ${ }^{4}, \mathrm{MD}, \mathrm{PhD}$; Malene Hollingdal ${ }^{4}, \mathrm{MD}, \mathrm{PhD}$; Lars Dittman ${ }^{5}$, $\mathrm{MSc}, \mathrm{PhD}$; Kim Dremstrup ${ }^{6}, \mathrm{MSc}, \mathrm{PhD} ;$ Birthe Dinesen $^{1}, \mathrm{MSc}, \mathrm{PhD}$

\footnotetext{
${ }^{1}$ Laboratory for Welfare Technology - Telehealth \& Telerehabilitation, Sport Sciences - Performance and Technology, Department of Health Science and Technology, Aalborg University, Aalborg East, Denmark

${ }^{2}$ The Danish Clinical Quality Program- National Clinical Registries (RKKP), Odense, Denmark

${ }^{3}$ Department of Psychology and Behavioral Sciences, Aarhus University, Aarhus, Denmark

${ }^{4}$ Cardiology Ward, Regional Hospital Viborg, Viborg, Denmark

${ }^{5}$ Networks Technology and Service Platforms, DTU Fotonik, Department of Photonics Engineering, Technical University of Denmark, Kgs Lyngby, Denmark

${ }^{6}$ Department of Health Science and Technology, Aalborg University, Aalborg, Denmark
}

\section{Corresponding Author:}

Cathrine Skov Schacksen, MSc

Laboratory for Welfare Technology - Telehealth \& Telerehabilitation, Sport Sciences - Performance and Technology, Department of Health Science and Technology

Aalborg University

Fredrik Bajers Vej 7, Bld A1

Aalborg East, 9220

Denmark

Phone: 4561285904

Email: cass@ @hst.aau.dk

\begin{abstract}
Background: More than 37 million people worldwide have been diagnosed with heart failure, which is a growing burden on the health sector. Cardiac rehabilitation aims to improve patients' recovery, functional capacity, psychosocial well-being, and health-related quality of life. However, cardiac rehabilitation programs have poor compliance and adherence. Telerehabilitation may be a solution to overcome some of these challenges to cardiac rehabilitation by making it more individualized. As part of the Future Patient Telerehabilitation program, a digital toolbox aimed at enabling patients with heart failure to monitor and evaluate their own current status has been developed and tested using data from a patient-reported outcome questionnaire that the patient filled in every alternate week for 1 year.
\end{abstract}

Objective: The aim of this study is to evaluate the changes in quality of life and well-being among patients with heart failure, who are participants in the Future Patient Telerehabilitation program over the course of 1 year.

Methods: In total, 140 patients were enrolled in the Future Patient Telerehabilitation program and randomized into either the telerehabilitation group $(\mathrm{n}=70)$ or the control group $(\mathrm{n}=70)$. Of the 70 patients in the telerehabilitation group, $56(80.0 \%)$ answered the patient-reported outcome questionnaire and completed the program, and these 56 patients comprised the study population. The patient-reported outcomes consisted of three components: (1) questions regarding the patients' sleep patterns assessed using the Spiegel Sleep Questionnaire; (2) measurements of physical limitations, symptoms, self-efficacy, social interaction, and quality of life assessed using the Kansas City Cardiomyopathy Questionnaire in 10 dimensions; and (3) 5 additional questions regarding psychological well-being that were developed by the research group.

Results: The changes in scores during 1 year of the study were examined using 1-sample Wilcoxon signed-rank tests. There were significant differences in the scores for most of the slopes of the scores from the dimensions of the Kansas City Cardiomyopathy Questionnaire $(P<.05)$. 
Conclusions: There was a significant increase in clinical and social well-being and quality of life during the 1-year period of participating in a telerehabilitation program. These results suggest that patient-reported outcome questionnaires may be used as a tool for patients in a telerehabilitation program that can both monitor and guide patients in mastering their own symptoms.

Trial Registration: ClinicalTrials.gov NCT03388918; https://clinicaltrials.gov/ct2/show/NCT03388918

(JMIR Cardio 2021;5(2):e26544) doi: 10.2196/26544

\section{KEYWORDS}

adherence; cardiology; cardiomyopathy; compliance; heart failure; heart; Kansas City Cardiomyopathy Questionnaire; monitoring; patient-reported outcome; patients; quality of life; rehabilitation; self-reporting; telehealth; telemonitoring

\section{Introduction}

Cardiovascular diseases are the leading cause of death worldwide [1]. In 2016, cardiovascular diseases were the cause of $31 \%$ of all deaths, which corresponded to 17.9 million people [1]. More than 37 million people worldwide have been diagnosed with heart failure (HF). Because of a poor prognosis, a high risk of disadvantageous outcomes, and increasing prevalence, HF is a growing burden on the health sector [2-4]. Cardiac rehabilitation aims to improve patients' recovery, functional capacity, psychosocial well-being, and health-related quality of life. The rehabilitation process combines activities such as physical activity, improved diet, weight control, psychosocial coping, and disease management [5]. However, cardiac rehabilitation programs have poor compliance and adherence. Patients may have poor means of transport to the rehabilitation facility, lack motivation, and feel that rehabilitation activities are not sufficiently individualized; all of these barriers negatively impact adherence to rehabilitation programs, which may in turn exacerbate symptoms including edema, fatigue, and shortness of breath, thus leading to readmissions [5,6]. Telerehabilitation (TR) may be a solution to overcome some of these challenges to cardiac rehabilitation $[7,8]$. TR is defined as the delivery of rehabilitation services through information and communication technologies [9].

TR may also be clinically relevant in obtaining health status measures from the patients. In turn, these measures add information regarding the severity of HF and may be used as an aid for clinical management [10]. Patient-reported outcomes (PROs) are clinical outcomes that increasingly focus on reducing the disease burden and improving general well-being and lifespan [11]. PRO can be used as a tool for screening and monitoring symptoms and assessing the course of the disease over time for clinicians to evaluate patient symptoms [12]. In a PRO regime, the outcome of a treatment is directly self-reported by the patient without registration or interpretation by a clinician [11]. Some of the outcomes are measurements of the patient's symptoms and health-related quality of life, which enable PROs to enhance targeted care and contribute to the optimal use of health care resources [11]. In this study, PRO from the Future Patient Telerehabilitation (FPT) program will be made available to patients as a tool for empowering them and increasing their knowledge of their own disease.

Through a user-driven innovation process, we have developed the FPT program for patients with HF. The overall purpose of the FPT program has been to increase the quality of life for patients with $\mathrm{HF}$ and to educate the patients to perform individualized monitoring to detect worsening of their own symptoms, thereby avoiding rehospitalization [13]. As part of the FPT program, a digital toolbox containing a PRO questionnaire was created. The purpose of the digital toolbox was to enable HF patients to monitor and evaluate their own current status over the 1-year duration of the TR program, thus enabling them to facilitate their contact with the hospital or their consulting general practitioners. To our knowledge, no previous studies that have investigated the clinical and psychological value of PROs in TR for patients with HF. A review from 2016 [14] on the use of PRO instruments in HF management concluded that the Minnesota Living with Heart Failure and Kansas City Cardiomyopathy Questionnaire (KCCQ) were useful PRO instruments in clinical care. However, more studies are needed on the value and interpretability of PRO instruments in clinical settings. The aim of this study is to evaluate the changes in quality of life and well-being among patients with HF, who are participants in the FPT program over the course of 1 year [13].

\section{Methods}

\section{Ethical Considerations}

This study utilized data from an intervention group that received TR (the TR group) in the FPT study, which was approved by the North Denmark Region Committee on Health Research Ethics (N-20160055) and the Danish Data Protection Agency. The study is registered on ClinicalTrials.gov (NCT03388918). The study was conducted in accordance with the tenets of the Helsinki declaration, and all participants signed an informed consent form prior to enrollment in the study.

\section{Context and Intervention of the Study}

The overall aim of the FPT study was to increase the quality of life of patients with HF by training them to perform individualized monitoring, which would enable to detect worsening of their symptoms in a timely manner, thereby avoiding rehospitalization [13]. The intervention of the FPT was divided into three phases (Figure 1): (1) TR and titration of medicine; as the adjustment of medication is specific to each patient, this phase will last 0-3 months; (2) TR at home and at a health care center or call center ( 3 months); and (3) follow-up with TR in everyday life (6 months). The TR program was based on a webpage called the HeartPortal [15], which is a digital toolbox that functions as an interactive learning module. The HeartPortal consists of (1) an information page containing text and short videos, (2) a communication platform that helps patients design their own TR plan and communicate directly 
with health care professionals, (3) visualization of measured values, and (4) a PRO questionnaire to be answered every second week. The measured values in HeartPortal included the patients' vital signs such as blood pressure, daytime and nighttime pulse rates, weight, step count, respiration, and hours of sleep. All data measured from the technologies were transmitted by the patient to HeartPortal. The data are illustrated as graphs and can be visualized and shared among patients, their relatives, and health care professionals. Upon enrollment in the study, the patients were instructed on how to use the PRO data to monitor their own disease and how to take necessary action if their symptoms worsened. The patients had the opportunity to contact the TR coordinator of the FPT program regarding any necessary action to be taken. Figure 2 shows the patients' PRO data in graphical format over a period of 2 months. The control group participated in the same 3 phases but without participating in the TR program; that is, they had no access to HeartPortal.

Figure 1. The 3 phases of the Future Patient Telerehabilitation study. PRO: patient-reported outcome.

\section{PRO questionnaire every second week}

\section{Phase I (0-3 months) Telerehabilitation and tritation of medicine}

Phase II (3 months)

Telerehabilitation at a

health care center or a call center

\section{Phase III (6 months) Everyday life with telerehabilitation}

Figure 2. A screen capture of HeartPortal. An illustration of the patient-reported outcome. Row 1: Information, My Treatment, My Status, Contacts, and Questions; Row 2: Weight, Blood Pressure, Pulse, Breathing, Sleep, Steps, and Well-being; Row 3: Time Intervals (3 months, 6 months, and Entire period); and Row 4 (bottom): Mood (light-green dot), Sleep (dark-green dot), Physical condition (orange dot), Symptom-free (red dot), Social contact (blue dot), and Mean (blue line).

\section{HjertePortalen Information Mitforløb Min status Kontakter Spørgsmål}

\begin{tabular}{|c|c|c|c|c|c|c|}
\hline Vægt & Blodtryk & Puls & Vejrtrækning & Søvn & Skridt & Velvære \\
\hline
\end{tabular}

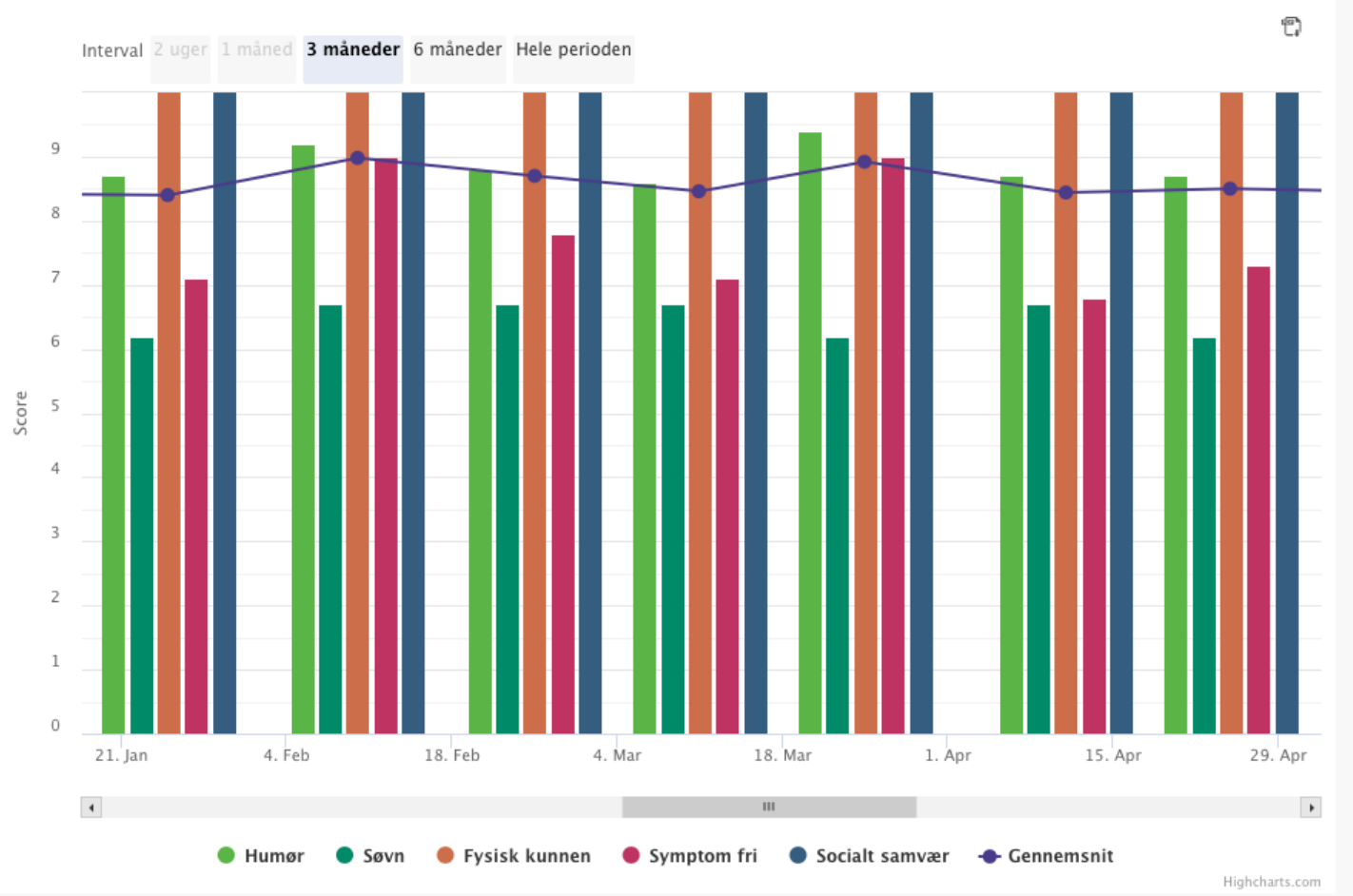

\section{Participants}

Participants were recruited from the cardiology wards at hospitals in Skive, Viborg, Silkeborg, and Randers in Denmark. Participants were recruited by a project nurse. The inclusion criteria for the FPT were the following: patients with HF with a New York Heart Association (NYHA) functional class of I-IV, of whom a maximum of $20 \%$ of the patients were of NYHA class I, $\geq 18$ years of age, able to care for themselves, and had basic computer skills. 


\section{Sample Size}

The sample size of the FPT study was determined to be 70 patients in each group (assuming a normal distribution), a power of $80 \%$, and a potential $10 \%$ dropout. This calculation was based on the KCCQ guidelines, which state that a "moderate" level of improvement is equal to a 10-point increase in the KCCQ score $[13,16]$. In this study of the FPT program, only the KCCQ outcomes from the intervention are reported. A comparison of the KCCQ results from both the intervention and control groups will be reported in a subsequent study on the evaluation of health utilizations.

\section{One Arm of a Randomized Controlled Trial}

In total, 140 patients were enrolled in the FPT and randomized into either the TR group $(n=70)$ or the control group $(n=70)$ [13]. This study only reports the findings of the TR group. Of the 70 patients in the TR group, $56(80.0 \%)$ answered the PRO questionnaire and completed the program, and these 56 patients constituted the study population. The randomization and follow-up procedure for the patients in the TR group are shown in the CONSORT (Consolidated Standards of Reporting Trials) diagram in Figure 3.

Figure 3. CONSORT (Consolidated Standards of Reporting Trials) diagram for the intervention group of the Future Patient Telerehabilitation trial.

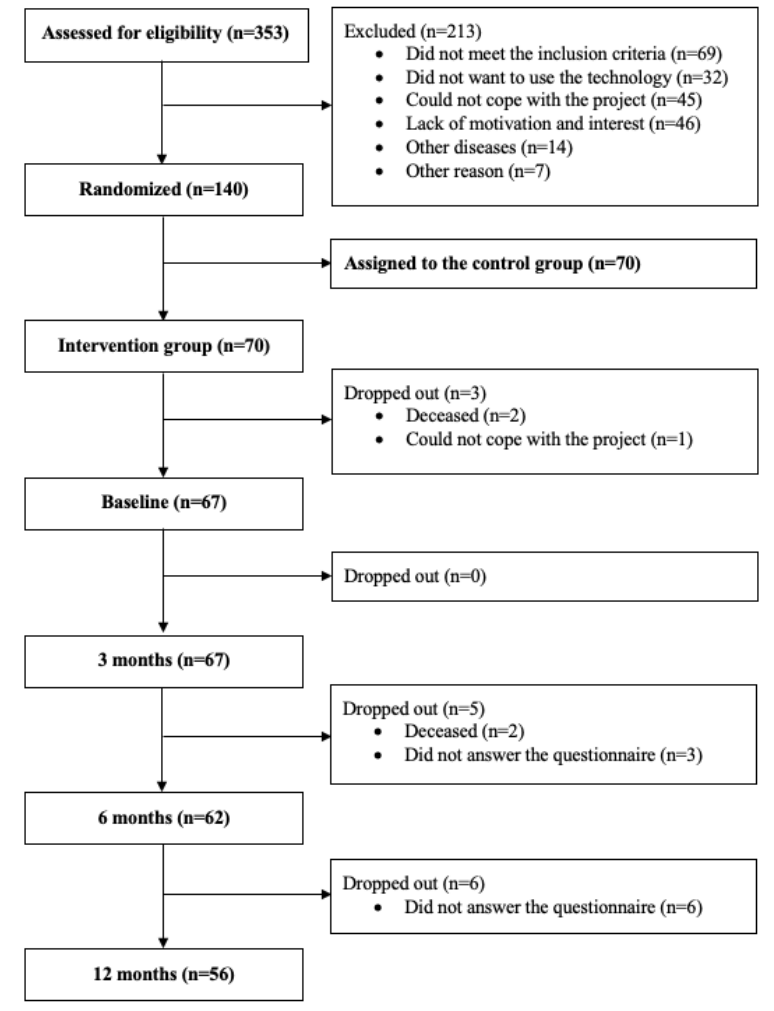

\section{Sociodemographic and Clinical Data}

Sociodemographic data (age, gender, education, employment status, and civil status) and clinical data (etiology of heart failure, NYHA class, ejection fraction, weight, blood pressure, and heart rate) were collected through self-reports or from the electronic patient record.

\section{PRO Measures}

The PRO questionnaire consisted of components from three questionnaires: (1) patients' sleep quality was evaluated using the Spiegel Sleep Questionnaire [17]; (2) physical limitations, symptoms, self-efficacy, social interactions, and quality of life were assessed using the validated KCCQ [16,18]; and (3) psychological well-being was evaluated using 5 additional questions developed by the research group.

\section{Spiegel Sleep Questionnaire}

Sleep quality was measured using the Spiegel Sleep Questionnaire [17]. The questionnaire consists of 6 questions regarding the patients' sleep patterns and sleep quality, with all items scored using a 5-point Likert scale. This is a validated sleep questionnaire and has been used in clinical studies [17,19].

\section{$\mathrm{KCCQ}$}

Measures of physical limitations, symptoms, self-efficacy, social interaction, and quality of life were self-assessed using the validated KCCQ. The KCCQ is a 23-item self-administered questionnaire with 15 questions. All items are scored on a 5-7-point Likert scale. There are 5 individual subscales, all of which, except for the self-efficacy subscale, are aggregated into the clinical and overall summary scores. The total score of the questionnaire is calculated by assigning an ordinal value to each response, with 1 as the lowest value, and then adding the values to obtain a scaled score for each domain. Accordingly, the scaled scores range from 0 to 100 , with a higher score indicating a better health status, fewer symptoms, and increased quality of life. Missing responses are assigned a value that corresponds to an average of the answered items within the domain $[16,20]$.

\section{Psychological Well-being}

The psychological well-being of the participants was measured using 5 questions developed by the research group. The 
questions were validated for clarity and understanding among patients with HF before use, in an iterative process. The questions were answered using a visual analogue scale, with 0 being the lowest value and 9 being the highest value. The 5-item psychological well-being scale was constructed on the basis of 5 different psychological aspects known to be of importance in $\mathrm{HF}$ (depression, anxiety, positive affect, hopelessness, and social support). We chose this approach, as it was not feasible to measure these factors using 5 psychological questionnaires in their entirety to measure these aspects. In addition, it has previously been shown that it may be possible to assess some of these factors through very brief questionnaires [21]. Furthermore, these questions were not intended as a means of diagnosis, but rather as indications of the patients' psychological status at the time of measurement.

\section{Data Collection}

All PRO questionnaire data were collected using Research Electronic Data Capture platform (Vanderbilt University). The questionnaires were made available on the internet to the patients on HeartPortal twice a month (between days 10-14 and 24-28 of the month). If the patients did not answer the questionnaire, the TR coordinator sent them a reminder.

\section{Data Preprocessing}

Data quality was ensured through data preprocessing. The time points for the data were converted from dates to a numeric variable - the questionnaire number. The PRO questionnaires were available to the patients twice a month at the aforementioned timepoints. Consequently, the questionnaires were still available for responses during the entire period and were not withdrawn after being completed by the patient. To correct for multiple responses to the same timepoint, the first responses within each time period were used in further analysis.

\section{Statistical Analysis}

Missing data were imputed by matching the responses from the questionnaires answered to those closest to the timepoint of the missing value [22]. Furthermore, our analyses showed that the imputation strategy did not significantly alter the results (these analyses are not included in this study). Nevertheless, missing data constitute a noteworthy problem. Furthermore, to account for missing data and varying durations of the 3 phases for the individual subjects in the study, the differences in scores in the 3 phases have been compared with trends for the subjects individually, in terms of slopes from linear regression analysis. In addition, when calculating the results for each dimension of the questionnaire, a minimum of half of the questions in each dimension was required. If less than half of the questions were answered, the results from that particular dimension would be excluded from the analysis [22].

All preprocessing steps and data analysis were performed using MATLAB (version R2019a, The MathWorks Inc). All statistical analyses were performed using IBM SPSS Statistics (version 26, IBM Corp).

Prior to analysis, the data were examined for normality of their distribution, using a Shapiro-Wilk test and by visual inspection of scatter plots. The 3 different questionnaires, as well as the subscales, comprising the PRO questionnaire in the FPT program were analyzed individually. To enable comparisons across subscales, scores were standardized by transforming each subscale to a range of 0-100 with higher scores indicating better health.

To evaluate changes in PROs during the 1-year duration of the intervention, Friedman tests were used. In case of significance, Wilcoxon sign-rank post hoc tests were used to determine in which phase the differences occurred during the 1-year duration.

\section{Results}

\section{Patient Characteristics}

Table 1 shows the baseline sociodemographic and clinical characteristics of patients in the TR group. These characteristics are depicted as either the number of patients or as mean (SD) values and ranges for the different parameters. 
Table 1. Clinical and sociodemographic data of the patients enrolled in the intervention group of the Future Patient Telerehabilitation program (N=67).

Variables Values

Age (years), mean (SD); range

$\operatorname{Men}(\mathrm{n}=51)$

Women $(\mathrm{n}=16)$

Men and women $(\mathrm{n}=67)$

Clinical parameters, mean (SD); range

Weight $(\mathrm{kg})$

Systolic blood pressure $(\mathrm{mmHg})$

Diastolic blood pressure $(\mathrm{mmHg})$

Heart rate (beats/minute)

Ejection fraction (\%)

Number of patients by New York Heart Association class, n (\%)

I

II

III

IV

Number of patients by the etiology ${ }^{\mathrm{a}}$ of heart failure, $n(\%)$

Ischemia
Idiopathy
Hypertension
Valvular heart disease
Alcoholism
Postpartum heart failure
Chemotherapy

Others

Marital status, n (\%)

Single or living alone

Married or living with a partner

Education level, $n(\%)$

Primary school

Unskilled

Skilled worker

High school

Bachelor's degree

Master's degree

Doctoral degree

Employment status, n (\%)

Unemployed

Sick leave

Working for $<20$ hours/week

Working for 20-36 hours/week

Working full-time for $37 \mathrm{~h} /$ week

Retired
62.18 (10.64); 35-81

60.31 (11.31); 43-81

61.73 (10.75); 35-81

85.34 (20.35); 56-166

124.42 (17.67); 84-172

78.97 (10.99); 48-122

78.70 (17.76); 46-119

31.80 (8.49); $10-45$

$10(14.9)$

42 (62.7)

13 (19.4)

$2(2.9)$

$32(47.8)$

17 (25.4)

$6(8.9)$

8 (11.4)

$0(0.0)$

$0(0.0)$

$0(0.0)$

18 (26.9)

$24(35.8)$

$43(64.2)$

4 (5.9)

$16(23.9)$

$30(44.8)$

5 (7.5)

$9(13.4)$

$2(2.9)$

$1(0.7)$

19 (28.4)

$5(7.5)$

2 (2.9)

$9(13.4)$

$32(47.8)$ 
${ }^{\mathrm{a}}$ Some patients have more causes of etiology of heart failure.

\section{Well-being in the 3 Phases of the Study}

The intervention in the FPT program was divided into 3 phases. The mean participation times for the TR patients in each phase were as follows: (1) TR and titration of medicine (2.37 months, SD 1.72 months), (2) TR at home and at a health care center or call center (3.43 months, SD 0.89 months), and (3) follow-up with TR in everyday life (5.77 months, SD 1.00 month). The patients completed $74.93 \%$ (SD $23.31 \%$ ) of the total number of questionnaires, with a minimum compliance of $14.81 \%$ and a maximum compliance of $100 \%$.

The Shapiro-Wilk test revealed that the data in the 13 different dimensions of the questionnaire were not normally distributed. Therefore, descriptive statistics for the data in 13 dimensions are presented in Table 2 as median (IQR) scores.

Changes in the median scores from each dimension for the 3 phases are illustrated in Figure 4. The dotted lines in Figure 4 demarcate the 3 phases. Each line in Figure 4, within each phase, represents 1 of the 13 dimensions of the questionnaires. As such,
Figure 4 illustrates the trend within each of the 3 phases and serves as a visual presentation of the data, showing that all 3 phases have an increasing slope. Based on the changes in the median scores shown in Figure 4, we observed a trend that indicates that the scores increased for most of the dimensions during the 3 phases, most notably in phase 1 .

Changes in PRO scores across the 3 phases of the study were examined using Friedman tests. As shown in Table 3, there were significant differences in scores on most of the dimensions in the KCCQ $(P<.05)$ during the 1-year intervention. Wilcoxon signed-rank post hoc tests were performed to examine the differences identified by the Friedman tests. These results are presented in Table 4 as $z$ scores, which are standardized scores that indicate the difference between preintervention and postintervention scores of the measure in question. As such, a negative $z$ score indicates a positive change over time (median scores for each phase are provided in Table 2). However, since no significant differences were observed across phases 2 and 3 , these results are not shown.

Table 2. Median (IQR) scores for all patient-reported outcome measures.

\begin{tabular}{|c|c|c|c|c|c|}
\hline Questionnaire & Dimension & $\begin{array}{l}\text { Median (IQR) score } \\
\text { in phase } 1(n=67)\end{array}$ & $\begin{array}{l}\text { Median (IQR) score } \\
\text { in phase } 2(n=62)\end{array}$ & $\begin{array}{l}\text { Median (IQR) score } \\
\text { in phase } 3(n=56)\end{array}$ & $\begin{array}{l}\text { Median (IQR) score } \\
\text { in all phases }(n=56)\end{array}$ \\
\hline Spiegel Sleep Questionnaire & Sleep & $58.33(12.50)$ & $58.33(12.50)$ & $57.20(12.50)$ & $58.33(12.50)$ \\
\hline Psychological well-being & $\begin{array}{l}\text { Psychological well- } \\
\text { being }\end{array}$ & $28.89(8.89)$ & $28.89(6.67)$ & $28.89(6.67)$ & $28.89(5.28)$ \\
\hline \multicolumn{6}{|c|}{ Kansas City Cardiomyopathy Questionnaire } \\
\hline & Physical limitations & $79.17(31.25)$ & $87.50(26.56)$ & 91.67 (29.17) & $88.75(29.17)$ \\
\hline & Symptom stability & $50.00(0.00)$ & $50.00(0.00)$ & $50.00(0.00)$ & $50.00(0.00)$ \\
\hline & Symptom frequency & $79.17(37.50)$ & $77.60(35.94)$ & $83.33(37.76)$ & $82.81(36.98)$ \\
\hline & Symptom burden & $75.00(3.50)$ & $75.00(25.00)$ & $83.33(35.42)$ & $83.33(31.25)$ \\
\hline & Total symptom score & $76.04(34.37)$ & $78.39(30.99)$ & $83.33(34.90)$ & $82.81(33.20)$ \\
\hline & Self-efficacy & $75.00(25.00)$ & $75.00(25.00)$ & $75.00(25.00)$ & $75.00(25.00)$ \\
\hline & Quality of life & $66.67(3.33)$ & $75.00(35.42)$ & $83.33(32.29)$ & 83.33 (33.33) \\
\hline & Social limitation & $66.67(46.88)$ & $80.21(32.29)$ & 83.85 (33.33) & $81.25(37.50)$ \\
\hline & $\begin{array}{l}\text { Overall summary } \\
\text { score }\end{array}$ & $72.14(32.42)$ & 77.34 (33.28) & $82.58(31.48)$ & $79.75(30.21)$ \\
\hline & $\begin{array}{l}\text { Clinical summary } \\
\text { score }\end{array}$ & $76.04(27.08)$ & $79.82(24.90)$ & 86.98 (32.03) & $85.02(30.14)$ \\
\hline
\end{tabular}


Figure 4. Changes in median scores from the 13 dimensions of the questionnaires. Dotted lines indicate a change in phase in the Future Patient Telerehabilitation program.

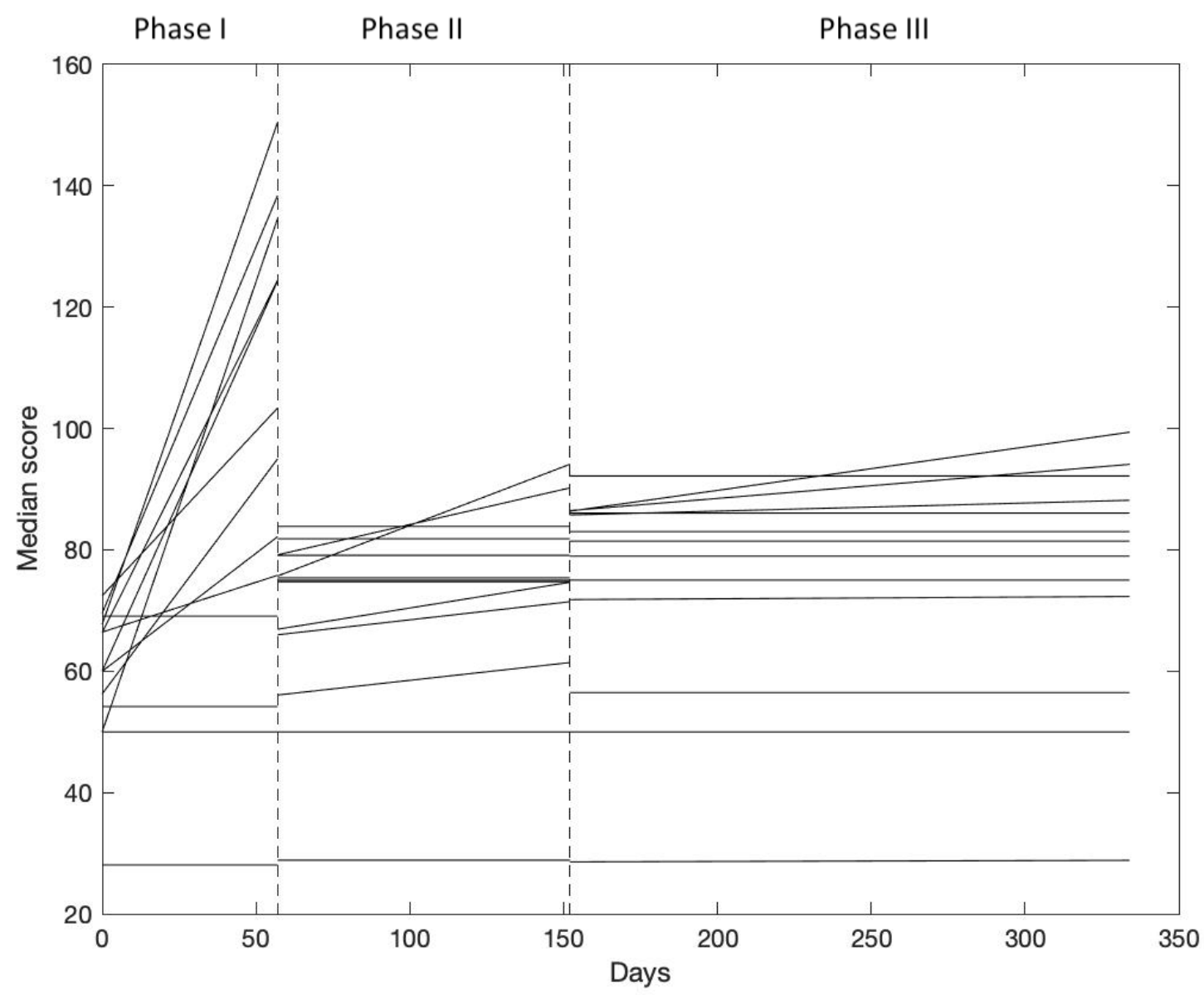

Table 3. Results of the Friedman test of the individual dimensions during 1 year.

\begin{tabular}{|c|c|c|c|}
\hline \multirow[t]{2}{*}{ Questionnaire } & \multirow[t]{2}{*}{ Dimension } & \multicolumn{2}{|c|}{ Changes in score over time } \\
\hline & & $\chi^{2}(d f)$ & $P$ value \\
\hline Spiegel Sleep Questionnaire & Sleep quality & $0.14(2)$ & .93 \\
\hline Psychological well-being & Psychological well-being & $0.04(2)$ & .98 \\
\hline \multicolumn{4}{|c|}{ Kansas City Cardiomyopathy Questionnaire } \\
\hline & Physical limitations & $9.25(2)$ & $.01^{\mathrm{a}}$ \\
\hline & Symptom stability & $0.75(2)$ & .69 \\
\hline & Symptom frequency & $16.75(2)$ & $<.001^{\mathrm{a}}$ \\
\hline & Symptom burden & $11.61(2)$ & $.001^{\mathrm{a}}$ \\
\hline & Total symptom score & $17.18(2)$ & $<.001^{\mathrm{a}}$ \\
\hline & Self-efficacy & $4.32(2)$ & .12 \\
\hline & Quality of life & $7.54(2)$ & $.02^{\mathrm{a}}$ \\
\hline & Social limitation & $19.75(2)$ & $<.001^{\mathrm{a}}$ \\
\hline & Overall summary score & $14.71(2)$ & $.001^{\mathrm{a}}$ \\
\hline & Clinical summary score & $19.54(2)$ & $<.001^{\mathrm{a}}$ \\
\hline
\end{tabular}

${ }^{\text {a }}$ Statistically significant at $P<.05$ (2-tailed). 
Table 4. $z$ scores and significance levels from the Wilcoxon signed-rank post hoc tests when testing for differences in trends on the Kansas City Cardiomyopathy Questionnaire in terms of slopes between the phases.

\begin{tabular}{|c|c|c|c|c|}
\hline \multirow[t]{3}{*}{ Dimension } & \multicolumn{4}{|l|}{ Slopes } \\
\hline & \multicolumn{2}{|c|}{ Phase I vs phase II } & \multicolumn{2}{|c|}{ Phase I vs phase III } \\
\hline & $z$ score & $P$ value & $z$ score & $P$ value \\
\hline Physical limitations & -2.41 & $.02^{\mathrm{a}, \mathrm{b}}$ & -2.62 & $.009^{\mathrm{a}, \mathrm{b}}$ \\
\hline Symptom frequency & -3.30 & $.001^{\mathrm{a}, \mathrm{b}}$ & -3.58 & $<.001^{\mathrm{a}, \mathrm{b}}$ \\
\hline Symptom burden & -1.74 & $.08^{\mathrm{a}}$ & -2.73 & $.006^{\mathrm{a}, \mathrm{b}}$ \\
\hline Total symptom score & -2.77 & $.006^{\mathrm{a}, \mathrm{b}}$ & -3.30 & $.001^{\mathrm{a}, \mathrm{b}}$ \\
\hline Quality of life & -1.69 & $.09^{\mathrm{a}}$ & -3.15 & $.002^{\mathrm{a}, \mathrm{b}}$ \\
\hline Social limitation & -2.85 & $.004^{\mathrm{a}, \mathrm{b}}$ & -3.33 & $.001^{\mathrm{a}, \mathrm{b}}$ \\
\hline Overall summary score & -2.27 & $.006^{\mathrm{a}, \mathrm{b}}$ & -3.83 & $<.001^{\mathrm{a}, \mathrm{b}}$ \\
\hline Clinical summary score & -3.76 & $<.001^{\mathrm{a}, \mathrm{b}}$ & -3.90 & $<.001^{\mathrm{a}, \mathrm{b}}$ \\
\hline
\end{tabular}

${ }^{\text {a }}$ Statistically significant at $P<.05$.

${ }^{\mathrm{b}}$ Higher slopes in phase I.

\section{Discussion}

\section{Principal Findings}

In the FPT program, the PRO questionnaire has served as a tool for patients on HeartPortal to help themselves monitor their well-being. The aim of this study was to evaluate the changes in quality of life and well-being for patients with HF who are participants in the FPT program over a 1-year period. We found that during the 1-year intervention, the following dimensions showed an increase in their median scores: physical limitation, symptom frequency, total symptom score, quality of life, social limitation, overall summary score, and clinical summary score. These changes were significantly different for most of the change in scores over time from the dimensions from the KCCQ.

In Figure 4, the increase in scores appeared more pronounced in the first phase, where patients start their TR and have their medication adjusted, compared to phases II (TR at home and rehabilitation at a health care center) and III (TR at home and follow-up in everyday life). However, patient scores increased continuously throughout all phases. This suggests that the intervention is most effective in phase I, as patients in this initial phase will tend to be more open-minded and motivated for changing their lifestyle and using the digital toolbox to empower themselves. As such, our results support the notion that rehabilitation should be initiated as soon as possible, preferably as part of the initial treatment phase, when patients are most motivated to initiate such changes. An analysis of the changes in scores during a year of TR showed significant differences in the scores on all dimensions of the KCCQ, except for self-efficacy. In general, these findings indicate that almost all scores from the different dimensions showed an increase and a significant difference for the overall change during 1 year of the intervention, thus indicating an improvement in the patients' health. We have not identified other studies reporting this type of improvement by using PRO questionnaires.
PRO questionnaires are normally used as a tool for research. They enable clinicians to obtain a better understanding of the patients' health status and serve as a clinical management tool [10]. In the FPT program, we deployed PRO as a tool for patients to monitor their own disease during their rehabilitation process. The patients answered almost $75 \%$ of all questionnaires for a period of 1 year, thus indicating a high degree of compliance with the PRO tool on HeartPortal. A study in Denmark [23] on HF and PRO has reported a compliance rate of approximately $50 \%$. In this study, however, the PRO questionnaire was used by patients to document their symptoms prior to visiting the HF outpatient clinic at the hospital. Thus, PRO served as a tool for clinicians as well [23]. This active use of PRO data by patients may help explain the high compliance rate in our FPT program. To our knowledge, no other TR studies have allowed for the possibility of evaluating the current status of patients with HF during 1 year with the use of PRO measures. Our data analysis has thus demonstrated that the PRO questionnaire can provide a cross-sectional view of the development of the patients' well-being and quality of life. The increase in the scores over time may indicate that the patients have used the PRO questionnaire to become more aware of their own symptoms and, therefore, be better equipped to navigate and cope with HF in their everyday lives. We have explored how patients have used the PRO questionnaire in the digital toolbox during their participation in the FPT program. This will be further documented in a subsequent study that describes patients' qualitative perspectives of using PRO as a part of TR.

A new study by Butler et al [24] in 2020 suggests that changes even smaller than 5-point improvements in KCCQ scores may be clinically significant. In the FPT study, the median (IQR) of the KCCQ clinical summary score increased from 76.04 (IQR 27.08) in phase I to 86.98 (IQR 32.03) in phase III, yielding a total median increase of more than 10 points. This indicates that the change in scores has clinical relevance, thereby indicating improvements in health based on the KCCQ results. However, no change was observed in the median scores of the Spiegel 
Sleep Questionnaire or the psychological well-being questionnaire. However, the FPT program was not designed to provide a specialized psychological intervention for psychological distress, such as anxiety and depression, but followed general guidelines for identifying and treating psychological distress in patients with HF.

\section{Limitations}

This study has limitations that should be considered. First, the timing of the PRO questionnaires may have been too frequent. In this study, it was collected every second week during 1 year, and this may have resulted in some patients skipping some of the questionnaires, thereby resulting in missing data. However, as some of the questionnaires referred to the patients' perceived symptoms over the previous 2 weeks, we considered this a relevant timeframe to detect changes in symptoms. Moreover, the responses from the PRO questionnaire provide subjective cross-sectional insights into the patients' well-being, which should be taken into consideration when evaluating their general well-being and when used in a clinical setting. In future studies, technological opportunities for mandatory responses may be used to generate more complete data from all participants.

It would have been valuable to include data from the control group for comparison. This study compared individual data over time, which is a valuable approach in identifying a trend. Nevertheless, on the basis of the available data, it was not possible to assess the development in quality of life and clinical aspects within the control group.

\section{Conclusions}

There was a significant increase in clinical and social well-being and quality of life during 1 year of participating in the TR program. These results suggest that PRO questionnaires may be used as a tool for patients in a TR program that can both monitor and guide the patients in mastering their own symptoms, improving their own well-being in a TR program, and enhancing their recovery.

\section{Acknowledgments}

We wish to thank the patients and all partners who participated in the study, including the health care centers and cardiology wards of regional hospitals in Viborg, Skive, Randers, and Silkeborg; the Danish Heart Association; Technical University of Denmark; Department of Psychology and Behavioral Sciences, Aarhus University; Department of Computer Science, Aalborg University; Centre for Innovative Medical Technology, Odense University Hospital; and the Laboratory for Welfare Technologies, Aalborg University. Furthermore, the authors wish to thank Aage and Johanne-Louis Hansen's Foundation for their financial support for this study. The Future Patient project was financed by Aage and Johanne-Louis Hansen's Foundation, Aalborg University, Viewcare, and partners in the study.

\section{Authors' Contributions}

$\mathrm{BD}, \mathrm{HS}, \mathrm{MH}$, and JR designed the study. CS, NH, JG, AD, and BD drafted the manuscript. All authors provided feedback on the manuscript and approved the final manuscript before submission.

\section{Conflicts of Interest}

None declared.

\section{References}

1. Cardiovascular diseases (CVDs). World Health Organization. 2021 Jun 11. URL: https://www.who.int/news-room/fact-sheets/ detail/cardiovascular-diseases-(cvds) [accessed 2021-06-22]

2. Ziaeian B, Fonarow GC. Epidemiology and aetiology of heart failure. Nat Rev Cardiol 2016 Jun;13(6):368-378 [FREE Full text] [doi: 10.1038/nrcardio.2016.25] [Medline: 26935038]

3. Ponikowski P, Voors AA, Anker SD, Bueno H, Cleland JGF, Coats AJS, ESC Scientific Document Group. 2016 ESC Guidelines for the diagnosis and treatment of acute and chronic heart failure: The Task Force for the diagnosis and treatment of acute and chronic heart failure of the European Society of Cardiology (ESC)Developed with the special contribution of the Heart Failure Association (HFA) of the ESC. Eur Heart J 2016 Jul 14;37(27):2129-2200. [doi: 10.1093/eurheartj/ehw128] [Medline: 27206819]

4. Ambrosy AP, Hernandez AF, Armstrong PW, Butler J, Dunning A, Ezekowitz JA, et al. The clinical course of health status and association with outcomes in patients hospitalized for heart failure: insights from ASCEND-HF. Eur J Heart Fail 2016 Mar;18(3):306-313 [FREE Full text] [doi: 10.1002/ejhf.420] [Medline: 26467269]

5. Anderson L, Taylor RS. Cardiac rehabilitation for people with heart disease: an overview of Cochrane systematic reviews. Cochrane Database Syst Rev 2014 Dec 12(12):CD011273 [FREE Full text] [doi: 10.1002/14651858.CD011273.pub2] [Medline: 25503364]

6. Tian J, Xue J, Hu X, Han Q, Zhang Y. CHF-PROM: validation of a patient-reported outcome measure for patients with chronic heart failure. Health Qual Life Outcomes 2018 Mar 20;16(1):51 [FREE Full text] [doi: 10.1186/s12955-018-0874-2] [Medline: 29554963]

7. Mampuya WM. Cardiac rehabilitation past, present and future: an overview. Cardiovasc Diagn Ther 2012 Mar;2(1):38-49 [FREE Full text] [doi: 10.3978/j.issn.2223-3652.2012.01.02] [Medline: 24282695] 
8. Dinesen B, Nielsen G, Andreasen JJ, Spindler H. Integration of Rehabilitation Activities Into Everyday Life Through Telerehabilitation: Qualitative Study of Cardiac Patients and Their Partners. J Med Internet Res 2019 Apr 15;21(4):e13281 [FREE Full text] [doi: 10.2196/13281] [Medline: $\underline{30985284]}$

9. Brennan D, Tindall L, Theodoros D, Brown J, Campbell M, Christiana D, et al. A blueprint for telerehabilitation guidelines. Int J Telerehabil 2010;2(2):31-34 [FREE Full text] [doi: 10.5195/ijt.2010.6063] [Medline: 25945175]

10. Heidenreich PA, Spertus JA, Jones PG, Weintraub WS, Rumsfeld JS, Rathore SS, Cardiovascular Outcomes Research Consortium. Health status identifies heart failure outpatients at risk for hospitalization or death. J Am Coll Cardiol 2006 Feb 21;47(4):752-756 [FREE Full text] [doi: 10.1016/j.jacc.2005.11.021] [Medline: 16487840]

11. Anker SD, Agewall S, Borggrefe M, Calvert M, Jaime Caro J, Cowie MR, et al. The importance of patient-reported outcomes: a call for their comprehensive integration in cardiovascular clinical trials. Eur Heart J 2014 Aug 07;35(30):2001-2009. [doi: 10.1093/eurheartj/ehu205] [Medline: 24904027]

12. Snyder CF, Aaronson NK. Use of patient-reported outcomes in clinical practice. Lancet 2009 Aug 01;374(9687):369-370. [doi: 10.1016/S0140-6736(09)61400-8] [Medline: 19647598]

13. Dinesen B, Dittmann L, Gade JD, Jørgensen CK, Hollingdal M, Leth S, et al. "Future Patient" Telerehabilitation for Patients With Heart Failure: Protocol for a Randomized Controlled Trial. JMIR Res Protoc 2019 Sep 19;8(9):e14517 [FREE Full text] [doi: 10.2196/14517] [Medline: 31538944]

14. Kelkar AA, Spertus J, Pang P, Pierson RF, Cody RJ, Pina IL, et al. Utility of Patient-Reported Outcome Instruments in Heart Failure. JACC Heart Fail 2016 Mar;4(3):165-175 [FREE Full text] [doi: 10.1016/j.jchf.2015.10.015] [Medline: 26874386]

15. Joensson K, Melholt C, Hansen J, Leth S, Spindler H, Olsen MV, et al. Listening to the patients: using participatory design in the development of a cardiac telerehabilitation web portal. Mhealth 2019;5:33 [FREE Full text] [doi: 10.21037/mhealth.2019.08.06] [Medline: 31620460]

16. Green CP, Porter CB, Bresnahan DR, Spertus JA. Development and evaluation of the Kansas City Cardiomyopathy Questionnaire: a new health status measure for heart failure. J Am Coll Cardiol 2000 Apr;35(5):1245-1255 [FREE Full text] [doi: 10.1016/s0735-1097(00)00531-3] [Medline: 10758967]

17. Spiegel R. Sleep and Sleeplessness in Advanced Age (Advances in Sleep Research, volume 5). New York, NY: SP Medical and Scientific Books; 1981.

18. Spertus JA, Conard MW, Rinaldi J, Tsuyuki R, Krumholz H, Pina I, et al. The kansas city cardiomyopathy questionnaire is sensitive to clinical change in congestive heart failure. J Am Coll Cardiol 2002 Mar;39:460. [doi:

10.1016/S0735-1097(02)82069-1]

19. Drewes AM, Bjerregård K, Taagholt SJ, Svendsen L, Nielsen KD. Zopiclone as night medication in rheumatoid arthritis. Scand J Rheumatol 1998;27(3):180-187. [doi: 10.1080/030097498440787] [Medline: 9645412]

20. Spertus JA, Jones PG, Sandhu AT, Arnold SV. Interpreting the Kansas City Cardiomyopathy Questionnaire in Clinical Trials and Clinical Care: JACC State-of-the-Art Review. J Am Coll Cardiol 2020 Nov 17;76(20):2379-2390 [FREE Full text] [doi: 10.1016/j.jacc.2020.09.542] [Medline: $\underline{33183512]}$

21. Everson SA, Goldberg DE, Kaplan GA, Cohen RD, Pukkala E, Tuomilehto J, et al. Hopelessness and risk of mortality and incidence of myocardial infarction and cancer. Psychosom Med 1996;58(2):113-121. [doi: 10.1097/00006842-199603000-00003] [Medline: $\underline{8849626]}$

22. Schafer JL, Graham JW. Missing data: our view of the state of the art. Psychol Methods 2002 Jun;7(2):147-177. [Medline: 12090408]

23. Rasmussen AA, Larsen SH, Jensen M, Berg SK, Rasmussen TB, Borregaard B, et al. Prognostic Impact of Self-Reported Health on Clinical Outcomes in Patients with Heart Failure. Eur Heart J Qual Care Clin Outcomes 2020 Mar 31:qcaa026. [doi: 10.1093/ehjqcco/qcaa026] [Medline: 32232437]

24. Butler J, Khan MS, Mori C, Filippatos GS, Ponikowski P, Comin-Colet J, et al. Minimal clinically important difference in quality of life scores for patients with heart failure and reduced ejection fraction. Eur J Heart Fail 2020 Jun;22(6):999-1005 [FREE Full text] [doi: 10.1002/ejhf.1810] [Medline: 32239794]

\section{Abbreviations}

FPT: Future Patient Telerehabilitation

HF: heart failure

KCCQ: Kansas City Cardiomyopathy Questionnaire

NYHA: New York Heart Association

PRO: patient-reported outcome

TR: Telerehabilitation 
Edited by $G$ Eysenbach; submitted 16.12.20; peer-reviewed by K Kastelic, T Wieringa, M Ferrer, J Knitza; comments to author 15.03.21; revised version received 13.04.21; accepted 19.05.21; published 02.07.21

Please cite as:

Skov Schacksen C, Dyrvig AK, Henneberg NC, Dam Gade J, Spindler H, Refsgaard J, Hollingdal M, Dittman L, Dremstrup K, Dinesen $B$

Patient-Reported Outcomes From Patients With Heart Failure Participating in the Future Patient Telerehabilitation Program: Data From the Intervention Arm of a Randomized Controlled Trial

JMIR Cardio 2021;5(2):e26544

URL: https://cardio.jmir.org/2021/2/e26544

doi: $10.2196 / 26544$

PMID: 34255642

(C) Cathrine Skov Schacksen, Anne-Kirstine Dyrvig, Nanna Celina Henneberg, Josefine Dam Gade, Helle Spindler, Jens Refsgaard, Malene Hollingdal, Lars Dittman, Kim Dremstrup, Birthe Dinesen. Originally published in JMIR Cardio (https://cardio.jmir.org), 02.07.2021. This is an open-access article distributed under the terms of the Creative Commons Attribution License (https://creativecommons.org/licenses/by/4.0/), which permits unrestricted use, distribution, and reproduction in any medium, provided the original work, first published in JMIR Cardio, is properly cited. The complete bibliographic information, a link to the original publication on https://cardio.jmir.org, as well as this copyright and license information must be included. 